\title{
Cardiac Stress Test Exercise Stage
}

National Cancer Institute

\section{Source}

National Cancer Institute. Cardiac Stress Test Exercise Stage. NCI Thesaurus. Code C69193.

The exercise level of a cardiac stress test. 